\title{
A ESCRITA DE SINAIS COMO INSTRUMENTO DE DESENVOLVIMENTO LINGUÍSTICO E IDENTITÁRIO PARA O SURDO
}

\author{
Francyllayans Karla da Silva Fernandes ${ }^{1}$ \\ Edneia de Oliveira Alves ${ }^{2}$ \\ Marianne Rossi Stumpf ${ }^{3}$
}

\begin{abstract}
Resumo: Sendo a língua de sinais uma manifestação cultural e identitário do surdo e possuindo ela a modalidade sinalizada e escrita, essa última modalidade no sistema signwriting. A escrita é um importante instrumento de empoderamento e desenvolvimento cognitivo e linguístico do surdo. Assim, defendemos que sua alfabetização deva ser realizada em sua escrita de sinais por ser sua primeira língua, assegurando-lhe a aquisição linguística como um período significativo, sem rupturas ou adaptações de uma língua (visualespacial) para outra (oral), com a qual ele não possui identificação. O objetivo geral desse trabalho foi verificar a aprendizagem da escrita de sinais pelo surdo. A pesquisa de natureza qualitativa, de caráter exploratório e delineamento de estudo de caso. O campo de pesquisa foi uma escola pública estadual e os participantes foram 6 sujeitos surdos. Analisou-se os dados por meio da técnica da migrogenética. Os dados indicaram que o surdo aprende com facilidade a escrita de sinais e que esses sujeitos se identificam com essa escrita por ser visoespacial.
\end{abstract}

Palavras-Chave: Escrita de sinais. Cultura. Identidade.

\section{THE WRITING OF SIGNS AS AN INSTRUMENT OF LINGUISTIC DEVELOPMENT AND IDENTITY FOR THE DEAF}

\begin{abstract}
The Sign language is a identity and cultural expression of the deaf en has signaled and write mode through SignWrinting. The write is en important instrument of empowerment and cognitive and linguistic development of the deaf. Thus, we defend that his literacy have to be by sign writing because it is his first language, ensure his language acquisition as a meaning moment, no breaks or adaptations from one language (viso-spatial) to another (oral) with that the deaf does not identify himself. The general objective was checked apprenticeship of the writing of signs by the deaf person. The research was made by qualitative nature, exploration character and study case design. Tha researche local in a state public school and the participants were 6 deaf subjects.
\end{abstract}

\footnotetext{
${ }^{1}$ Pedagogia. Letras-Libras. Psicologia. Mestranda em Educação pela Universidade Federal da Paraíba (UFPB).francyllayans@gmail.com.

${ }^{2}$ Letras - Inglês / Português. Mestre em Psicologia Social. Doutora em Psicologia Social. Professora de Libras na Universidade Federal da Paraíba (UFPB). edneiaalvesufpb@gmail.com.

${ }^{3}$ Tecnologia em Informática. Educação dos Surdos. Doutora em Informática na Educação. Professora Adjunta na Universidade Federal de Santa Catariana (UFSC).stumpfmarianne@gmail.com.
} 
The dates was analised by microgenetic techiniques which indicated that the deaf learn sign writing easily and theses people identify themselves with this king of write because of viso-spatiality.

Keywords: Signwriting. Culture. Identity.

\section{Introdução}

A Língua Brasileira de Sinais como primeira língua da comunidade surda trouxe para essas pessoas inúmeras possibilidades dentro da sociedade, principalmente, em sua formação básica. A educação é um direito constitucional previsto a ser garantido para todos, entretanto, durante anos foi negado de forma sutil e velada, uma vez que a Língua Brasileira de Sinais (Libras) nunca foi abordada especificamente no ambiente escolar como a língua natural da comunidade surda e, hoje, essa história se repete na maioria das escolas regulares nas quais a língua de sinais não é inserida como disciplina curricular.

No percurso histórico de lutas há vitórias e derrotas. O reconhecimento oficial da Libras através da lei 10.436/2002, regulamentada pelo decreto 5.626/05 traz a exigibilidade de que a educação bilíngue deve ser estabelecida para o melhor desempenho acadêmico da pessoa surda. Segundo Alves e Alberto (2016), os documentos de ordenamento jurídico possuem como exigibilidade que seja ofertada uma educação bilíngue para o surdo em que a Libras seja sua primeira língua e o português escrito sua segunda língua e nela considera-se os aspectos culturais do surdo. Entretanto, na prática, não há o respeito a essa ordenação linguística para aquisição.

Com base nessas inquietações e na importância que a língua de sinais tem para o surdo, essa pesquisa surgiu com o objetivo de verificar a aprendizagem da escrita de sinais no sistema SignWriting pelo surdo, analisando o interesse dos mesmos pela escrita de sinais, bem como identificando as facilidades e as dificuldades presentes nesse processo de ensino e aprendizagem da escrita de sinais e, assim, observar a identificação do sujeito surdo com a escrita de sua língua.

A pesquisa foi de natureza qualitativa, de caráter exploratório e delineamento de estudo de caso. O campo de pesquisa foi uma escola pública estadual situada em um município do Rio Grande do Norte que fornecia ensino 
em nível fundamental II e EJA atendia 261 alunos, dentre os quais 1 era surdo. Além desse aluno, a escola atendia mais 5 alunos surdos de outras escolas em sua sala de recurso. Todos os alunos surdos se tornaram participantes da pesquisa. Suas idades variavam de 13 a 34 anos de idade, 5 eram das séries

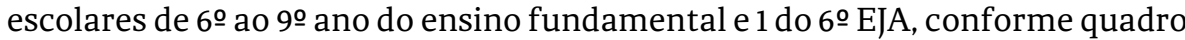
1. Os dados foram analisados por meio da técnica da migrogenética por meio da qual buscou-se compreender o processo de ensino aprendizagem da escrita de sinais, verificando as facilidades e dificuldades e o interesse pelo conteúdo. Para avaliação de rendimento foram analisados os testes aplicados para esse fim.

A língua de sinais representa a comunidade surda, segundo Alves e Paixão (2018), ela é um artefato cultura do povo surdo, é o elemento central de sua produção humana e é marca identitária e da formação de cultura surda. De acordo com Alves (2018), a Libras possui modalidade sinalizada e escrita. Na figura 1, há o desenho do sinal 'azabumba' representando a sinalização do sinal e sua representação escrita.

Figura 1: sinal azabumba

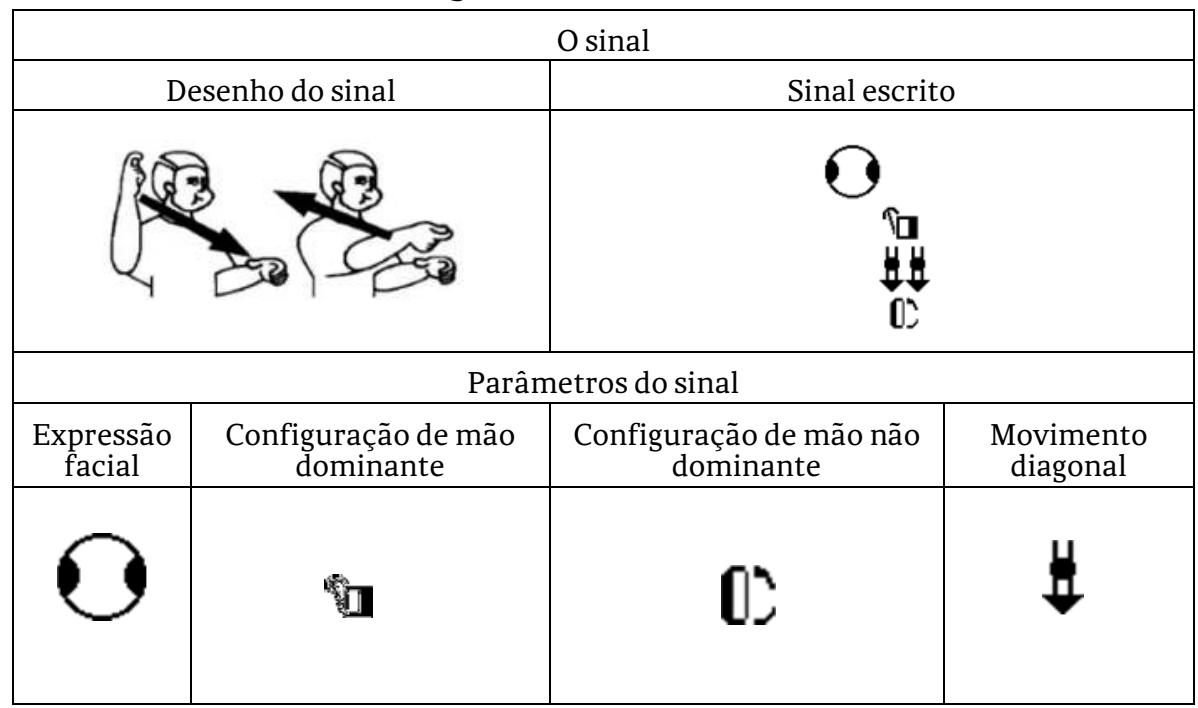

Fonte: Capovila, 2008. 
Vemos nessa figura, o sinal é uma representação simbólica do objeto, mesmo ele possuindo motivação incônica. Lederberg, Schick e Spencer (2013) nos diz que a gesticulação constrói o significado e que essa é realizada por meio de movimentos de corpo, braços e faciais e que possui uma gramática de pronominalização, verbal, adjetivos e outros. A representação escrita desse sinal dá conta de todos os elementos da Libras sinalizada.

O sistema que adotamos para a escrita de sinais é o SignWriting. Conforme Morais (2016), esse sistema foi criado por Valerie Sutton e surgiu na Suécia. Essa escrita, Segundo Alves a Paixão (2018), representa graficamente o sinal que tem como referência a visualidade, assim, representa os aspectos de formação do sinal, o que possibilita registrar por escrito os classificadores e as expressões faciais e corporais

A escrita é uma manifestação formal dos mais variados tipos de letramento, tornando-se um bem social, a qual é fundamental para o cotidiano e é essencial para a sobrevivência dentro do mundo moderno (MARCUSCHI, 2001). Nesse sentido, torna-se indispensável para todo cidadão. Considerando que o surdo possui a Língua Brasileira de Sinais (Libras) como primeira língua, é ela que deve ser ensinada em primeiro plano para o surdo. Porém, seja na escola específica para surdos ou na escola regular, a educação básica tem tentado alfabetizar o surdo em língua portuguesa ao longo de todos esses anos. Esse é um movimento que tem como base a sobreposição do valor da língua oral sobre a língua de sinais, favorecendo a uma educação de fundamento oralista, conforme Alves e Alberto (2019), repetindo a filosofia de educação oral ainda praticada no início do século XX.

Por décadas existem falhas que não foram sanadas e continuam a ser perpassadas. A criança surda é submetida a mesma estratégia de alfabetização em língua portuguesa adotada para ouvintes (QUADROS; SCHMIEDT, 2006). No entanto, a Língua Portuguesa representa a cultura oral diferente da cultura surda que é baseada na visualidade. Portanto, a alfabetização do surdo em escrita do português é uma adaptação que não supre a necessidade de expressão cultural do povo surdo.

Ter acesso a uma alfabetização em escrita de sinais é acessar sua própria cultura. , que traz na língua de sinais todos os elementos culturais desse povo, ou seja, o registro escrito dos pensamentos do indivíduo surdo. É o 
respeito ao sujeito surdo e a uma cultura de uma coletividade surda porque, segundo Strobel (2009), a cultura surda é o modo como o Surdo enxerga, entende e identifica o mundo, com o intuito de transformá-lo para que se torne condizente a sua construção identitária.

No tocante à cultura surda e seus elementos, a língua é o maior veículo de transmissão cultural, sendo a língua de sinais a língua natural do povo surdo e importante instrumento de desenvolvimento cognitivo. Desta forma, aceitar a língua da comunidade surda implica em aceitar a cultura desse povo também, pois a língua e a cultura estão extremamente relacionadas, sendo ela a do sujeito que participa das duas comunidades, surdas e ouvintes (STROBEL, 2009). Dentro desse processo, percebe-se que Pode-se explicar esse apresso pelo sinal-nome a partir da cultura surda.

Ao internalizar as experiências fornecidas pela cultura, a criança reconstrói individualmente os modos de ação realizados externamente e aprende a organizar os próprios processos mentais (VYGOTSKY, 1984 apud OLIVEIRA, 1997). Partindo desse ponto de vista e pensando na apropriação cultural, gramatical e na facilitação de desenvolvimento cognitivo, a modalidade escrita da língua de sinais desempenha um papel importante no desenvolvimento da pessoa surda.

Defendemos dessa forma, porque ela é uma modalidade visual e representante dos elementos linguísticos da Libras da modalidade sinalizada desta língua, tais como os elementos quirêmicos formados pelos parâmetros (Configuração de Mãos, Movimentos, Direção, Expressão Facial/Corporal e os Pontos de Articulação), os contados, os aspectos semânticos, pragmáticos e discursivos, os quais exercem uma função representativa significativa para os seus usuários. Além desses aspectos, ela representa a cultura do povo surdo, como afirma Oliveira (2016), pois na literatura em escrita de sinais há a apresentação do sinal-nome, demonstra o processo de aquisição e uso da língua e variação linguística.

Desta forma, através do contato com sua língua escrita, o sujeito surdo terá oportunidade de apreender relações de significado entre a sinalização e a escrita da língua, proporcionando um maior desenvolvimento linguístico e cognitivo (DALLAN, 2009). Como afirma Piaget (1970), para a construção do conhecimento, faz-se necessário a relação entre o sujeito e o 
objeto. Assim, a pessoa surda necessita do favorecimento da sua atividade mental lendo, escrevendo e transcrevendo a língua de sinais.

Conforme Vygotsky (2008), adquirir a escrita contribui para o uso consciente das habilidades linguísticas, sendo a escrita desenvolvida em toda sua plenitude e a fala no interior de maneira condensada e abreviada. Ainda para Vygotsky, o saber precisa da experiência, por isso a cultura e a história assume um papel de destaque no processo de aprendizagem e a linguagem é o maior vínculo de socialização e assim também instrumento de intermediação do conhecimento e a escrita responsável pelo desenvolvimento do pensamento, sendo fundamental ao surdo o acesso à escrita de sinais.

No que se refere ao processo de alfabetização do surdo acreditamos que não pode ser ofertada ao surdo como se faz com o ouvinte porque ao invés de oferecermos a equidade de oportunidade estaremos apenas contribuindo com a hegemonia da língua portuguesa. Entendemos como Marcuschi (2001) que o ensino para o letramento envolve a prática social da leitura e o ensino de alfabetização promove a aquisição do código. Ao mesmo tempo, compreendemos da mesma forma que exposto por Leal e Nascimento (2019) de que o ensino da palavra precisa ser considerando o mundo, ou seja, precisamos considerar o contexto sócio-histórico e discursivo do estudante. Nessa linha de pensamento, Leal e Nascimento nos diz que o ensino precisa considerar os gêneros textuais e discursivos.

\section{Metodologia da pesquisa}

A pesquisa foi de caráter exploratório que tem como finalidade uma maior familiaridade com o problema (GIL, 1991, p. 46) e busca descobrir ideias e intuições, para se adquirir maior familiaridade com o fenômeno pesquisado (SELTIZ et al. 1965). Para a realização dessa pesquisa também adotamos a natureza de estudo qualitativo porque, segundo Araújo e Oliveira (1997), com ele pode-se realizar estudos descritivos com o fenômeno em ambiente natural. $\mathrm{O}$ delineamento constitui-se como estudo de caso, por favorecer a uma pesquisa empírica e observar as variáveis interferentes e intervenientes. A partir do objetivo desse estudo nos interessa entender como acontece o processo de 
alfabetização em escrita e de que forma ele impacta na habilidade de aquisição do código escrito da própria língua pelo surdo.

\section{Caracterização campo de pesquisa e da amostra}

O estudo foi realizado em uma escola localizada no Município de Canguaretama-RN, recebia 261 alunos de diversas comunidades com grande maioria pertencentes a classe social $\mathrm{D}$, funcionários de usinas e pescadores. Atendia os anos escolares do 6 ㅇ ao 9 ㅇ ano nos turnos manhã e tarde e à noite tem a modalidade EJA que atende do 6 ㅇ ano do ensino fundamental II ao $3^{\circ}$ ano do ensino médio. Com relação aos alunos surdos, havia apenas 1 cursando 7은 ano.

Na escola, nenhum dos funcionários da instituição se comunicava em Libras e apenas a partir de 2015 os alunos passaram a ter a tradução da aulas para Libras. Entretanto, a escola tinha uma sala de recurso que atendia 5 exalunos da escola e esse auno da escola por ser um polo de atendimento para as pessoas com deficiência. Os surdos tinha atendimento com a professora de Libras uma vez por semana por 2 horas, sendo o ensino de Libras realizado a cada quinze dias revezando o horário com o ensino de português como L2. Esse publicou tornou-se a amostra da pesquisa, ver as características no quadro 1. Todos eles possuíam como fonte de renda o benefício de proteção continuada (BPC).

\begin{tabular}{|c|c|c|}
\hline Participante & Idade & Série \\
\hline 1 Feminino & 13 & 60 \\
\hline 2 Feminino & 15 & 9o \\
\hline 3 Masculino & 15 & 9o \\
\hline 4 Masculino & 21 & $7 ㅇ$ \\
\hline 5 Masculino & 23 & 9o \\
\hline 6 Masculino & 34 & 6을 \\
\hline
\end{tabular}




\section{Procedimentos}

Essa pesquisa foi uma replicação de três estudos de caso realizados no ano de 2016 realizados por Encarnação (2016), Alves (2016) e Lima (2016), as quais utilizaram também a aplicação de rendimento da professora Marianne Stumpf, que trata da escrita de sinais no sistema SignWriting. Para a realização do estudo foi conversado e autorizado pela diretora. Para teste do procedimento as aulas foram ministradas aos participantes da pesquisa na sala de recurso aos quais a pesquisadora atendia. Para verificação de rendimento foi aplicado o teste da professora Marianne Stumpf que verificava a aprendizagem de escrita de vocábulos, na qual o aluno precisa escolher o sinal escrito correto para determinada imagem. Além desse teste, utilizamos as lições, atividades e um diário de bordo.

Foram realizadas quatro aulas de escrita de sinais no sistema SignWriting com duração de 60 minutos, tendo o auxílio de data show para exposição das imagens que demonstram a língua de sinais escrita, utilizamos material pedagógico (lápis, papel, borracha), atividade impressa, ao fim das quatro aulas aplicamos o teste de verificação de rendimento.

Os dados foram analisados por meio da técnica Microgenética que possibilita observar como se dá o processo de ensino-aprendizagem, identificando as habilidades comunicativas que corroboram com esse processo, bem como os que dificultam a aprendizagem (BRANCO; SALOMÃO, 2001). Assim, buscou-se a compreensão sobre a forma em que o processo de ensino-aprendizagem da escrita de sinais com os participantes da pesquisa ocorreu, a interação dos participantes com a escrita no decorrer das aulas, o interesse diante das atividades propostas, as dificuldades e facilidades para aceitação da escrita de sinais, crescido da verificação dos resultados baseados no teste de rendimento aplicado no final da sequência das quatro aulas ministradas.

\section{A aprendizagem de escrita de sinais}

Os dados aqui apresentados foram adquiridos das aulas ministradas pela pesquisadora utilizando-se da Libras como meio de comunicação, pois, possui fluência na mesma. Os conteúdos abordados foram: parâmetros da 
Libras em escrita de sinais (configuração e orientação de mão e movimentos tipos de contato e leitura e compreensão de texto). Iniciou-se por meio do ensino do alfabeto para construção do seu próprio e o sinal-nome com atividade em roda de conversa com autoapresentação. Foi trabalhada decodificação dos movimentos presentes em cada sinal e a diferenciação entre os parâmetros nos sinais escritos. Também foi trabalhada em aula expositiva a leitura e compreensão da tradução em escrita de sinais do poema "No meio do caminho" de Drummond.

A pesquisa foi realizada com um público adolescente, porém, as referências norteadoras da pesquisa são de estudos com crianças, pois não encontramos referencias para aprofundamento do tema nessa faixa etária, o que revela a necessidade de pesquisas desses tipos com adolescentes.

Na primeira aula, foi trabalhada a escrita de sinais do nome próprio e do sinal-nome dos alunos, com isso trabalhamos o alfabeto manual escrito e as configurações e orientações de mão, conforme figura 2.

Figura 2-Alfabeto em português e em escrita de sinais

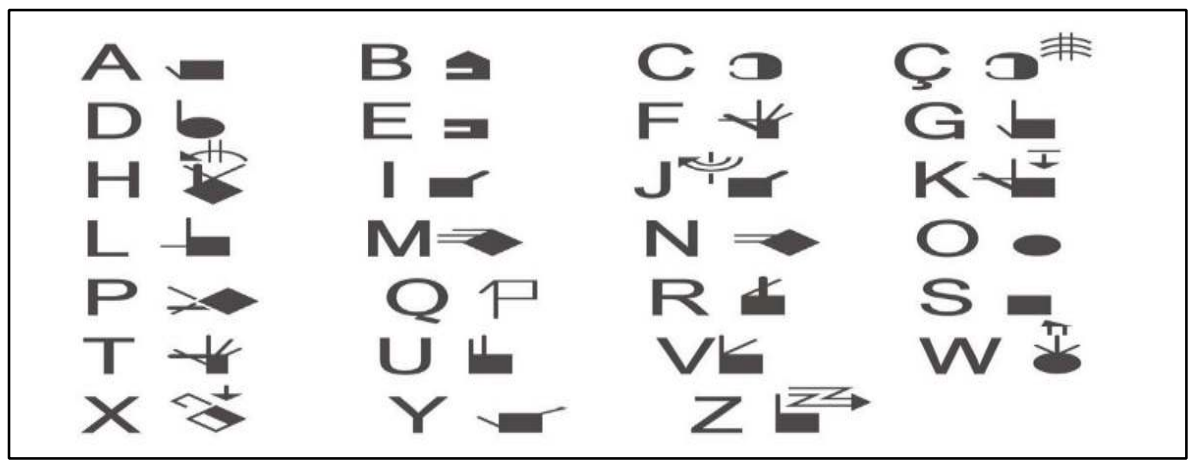

Fonte: http://www.signwriting.org.

Nem todos os participantes dominavam a datilologia da língua de sinais, assim trabalhamos também alguns nomes soletrados para contato inicial com a escrita de sinais. Esse trabalho facilitou o entendimento da escrita do próprio nome na datilologia escrita conforme figura 2. Esse dado nos revela que o ensino da palavra mundo, como ressaltado por Leal e Nascimento (2019), produz uma aprendizagem significativa. Também nos revela que a escrita do 
próprio sinal-nome causou mais interesse que a escrita do nome de batismo. Corroborando com Alves e Moura (2015) que o sinal-nome relaciona-se com a identidade surda por possuir afinidade com a cultura surda. Porém, é importante que se inicie pela escrita do sinal-nome por ser ele o conhecimento prévio, conforme preceitos de Vygotsky (2008). Embora o surdo não negue seu nome de nascimento e tenha criado uma forma de representá-lo com as mãos.

Figura 2- Nome e Sinal-Nome

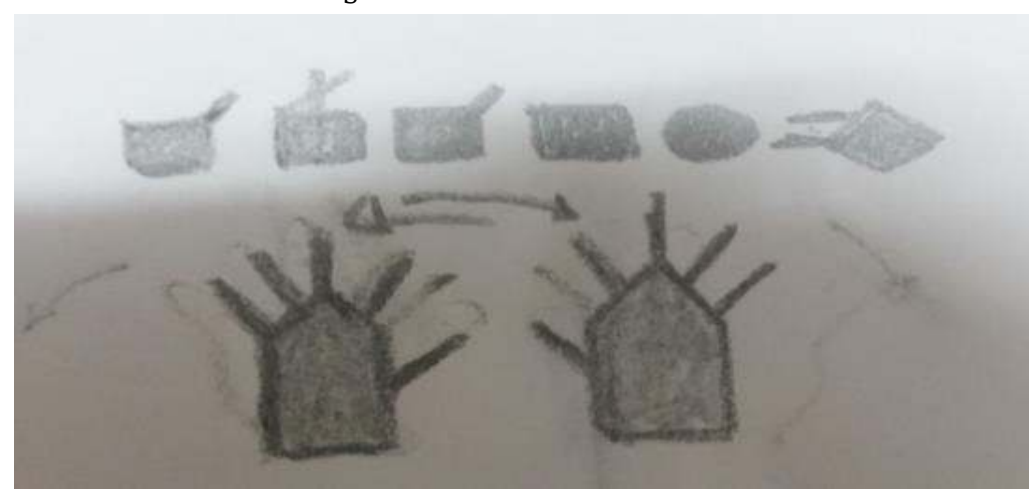

Fonte: Dados da Pesquisa

Nesse sentido, fomos dando continuidade aos estudos da escrita de sinais. A segunda e terceira aula teve como conteúdo a escrita dos parâmetros da Libras: Configuração de Mão las e suas possibilidades de orientação; Movimento em plano chão e parede, que são algumas das convenções da escrita de sinais e símbolos de contato: Tocar, Escovar e Esfregar em Círculo, com o objetivo de estabelecer distinção entre esses elementos a partir de palavra do cotidano do aluno, tais como:

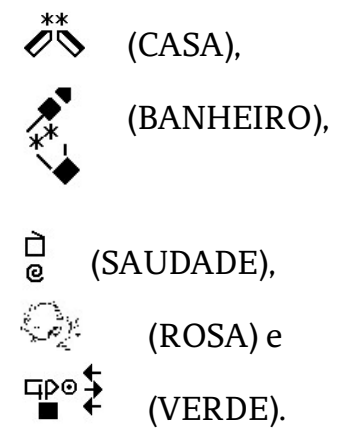


Esse momento foi uma oportunidade de relacionar os conhecimentos práticos dos alunos, construídos em suas vivências de sinalização com a aquisição dos conhecimentos teóricos acerca da escrita dos sinais, conforme figura 4.

Figura 4- Orientação básica da palma da mão

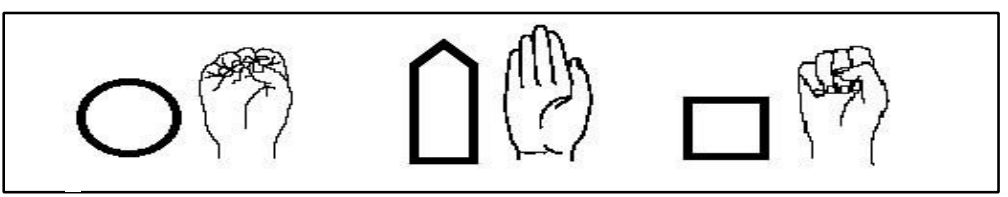

Fonte: http://www.signwriting.org

Nessa aula, percebemos que os alunos utilizavam o conhecimento prévio da sinalização, apoiavam-se na mediação da professora e conseguiam associavam a escrita dos parâmetros com a sinalização. Mais uma vez os alunos demonstraram total entendimento, estabelecendo rápida e significativa compreensão da escrita de cada sinal e aos seus parâmetros, confirmando o que Alves, et al (2015, p. 112) quando afirmaram que o surdo vê no papel a sua língua realizada com as mãos e que a escolha por trabalhar com sinais do cotidiano facilita a aquisição do código escrito.

Na quarta aula, foi trabalhada a tradução em escrita de sinais do poema "No meio do caminho" de Carlos Drumond de Andrade. Inicialmente, trabalhamos a leitura e compreensão e logo após fizemos uma aula expositiva para reapresentação dos parâmetros: Configuração de mão, Orientação da mão, Movimento e Tipos de contato presentes nos sinais que compunha o poema. Dessa forma, trabalhamos formação de sinais a partir de uma unidade de sentido: o poema, com o objetivo de proporcionar o reconhecimento e a interpretação dos parâmetros da escrita de sinais dentro do texto. Para que o processo de leitura e interpretação acontecesse, foi realizada a apresentação dos movimentos de seta e das noções de tipo de contato e a reapresentações dos parâmetros já estudados, focando nas orientações das mãos dos sinais propostos. E, por fim, o símbolo de contatos, focando no contato arrastar, pegar, bater e escovar conforme a figuras 5 . 
Figura 5-Parâmetros encontrados no poema

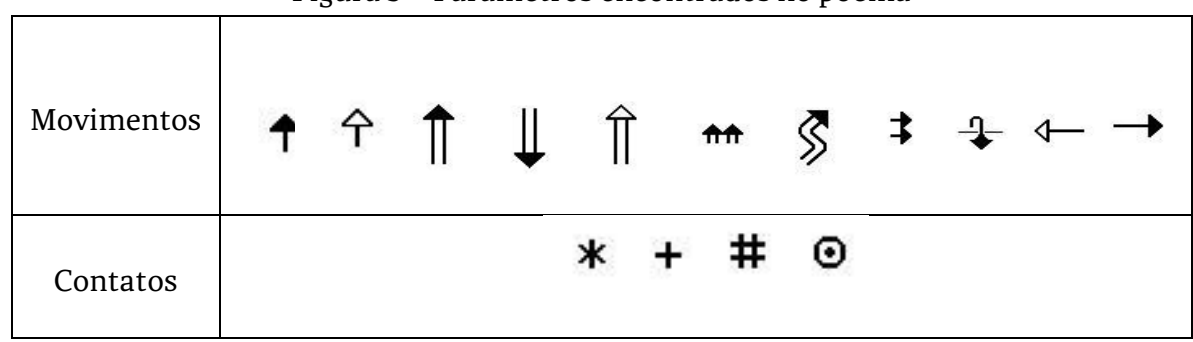

Fonte: Dados da pesquisa

Esse dado nos indica que é possível trabalhar a alfabetização na perspectiva do letramento, conforme Marcuschi (2001) a alfabetização relaciona-se à aquisição do código e o letramento ao uso da escrita nas práticas sociais. Portanto, nos momentos da aprendizagem do código é preciso apresentar-lhe uma leitura significativa, em nosso caso escolhemos um gênero literário. Verificamos também que a escrita de sinais é útil também no acesso à literatura brasileira e no processo de desenvolvimento de leitura do sujeito surdo, pois, mesmo estando em fase inicial de aprendizagem da escrita de sinais não apresentaram nenhuma dificuldade na identificação dos sinais escritos e na interpretação do texto, o que seria diferente se o mesmo estive escrito em língua portuguesa. Além dessas questões, com esse trabalho oferecemos ao aluno a leitura por prazer e para a reflexão sobre a realidade que é uma das funções do trabalho com literatura.

Para a finalização de nossa pesquisa em busca da verificação da aprendizagem da escrita de sinais no sistema SignWriting pelo surdo, aplicamos o teste de verificação de rendimento. 4 deles resolveram rapidamente com $100 \%$ de acertos e 2 demoraram um pouco mais, porém, tiveram $80 \%$ de acertos. O fato de que dois dos participantes terem tido um rendimento, embora muito bom, menor que os demais, podemos considerar se deve à pouca fluência que ambos possuem na língua de sinais. Esses dados corroboraram com os resultados dos estudos de Encarnação (2016), Alves (2016) e Lima e Alves (2018).

O bom rendimento da turma indicou que a alfabetização dos surdos deve acontecer através da escrita de sinais, pois mesmo diante de uma nova modalidade de escrita, os participantes revelaram facilidade em apropriação 
dessa escrita, uma vez que através do conhecimento de sua própria língua é possível adquirir outros conhecimentos de maneira mais rápida. Por isso, Stumpf (2013, p. 63) sobre o processo de aprendizagem da Escrita de Sinais afirma:

Nós, surdos, precisamos de uma escrita que represente os sinais visuais - espaciais com os quais nos comunicamos, não podemos aprender bem uma escrita que reproduz os sons que não conseguimos ouvir.

A facilidade em aprender a escrita de sinais foi um dado importante, tendo em vista que há a crença de que o surdo não aprende a escrever. Essa pesquisa indicou que a dificuldade presente nos discursos dos professores de surdos está relacionada à escrita da língua portuguesa e uma hipótese para a explicação desse fenômeno é que as dificuldades são geradas pela inversão do processo de alfabetização, pois, ao surdo é imposta a aquisição da escrita de uma língua diferente da sua língua natural. A facilidade no processo de ensino/aprendizagem foi encontrada em todas as pesquisas realizadas sob orientação da professora Edneia Alves.

A reação de aceitação da escrita de sinais SignWriting ocorreu desde a primeira exposição, uma vez que os alunos reagiram sem receio, pois os mesmos agiram naturalmente diante da exposição do conteúdo da escrita de sinais, corroborando com os dados dos estudos replicados nessa pesquisa. É importante destacar que todas as aulas contaram com a exposição visual, sendo esse elemento fundamental para o ensino da pessoa surda que possui a capacidade de leitura visual. Como pontua Reily (2003, p. 16) “Crianças surdas em contato inicial com a Língua de Sinais necessitam de referências da linguagem visual com as quais tenham possibilidade de interagir, para construir significado".

E desta forma a interação da escrita de sinais com o contato visual, acentuou o desejo pelo conhecimento dos parâmetros necessários para escrita dos sinais, o que ficou ainda mais ressaltado na interpretação do poema, que deu aos surdos a possibilidade de através de sua própria língua ler um texto, interpretar, identificar sinais e construir significado. 
O contato do surdo com a escrita de sinais revela a importância dessa construção para o desenvolvimento do pensamento superior complexo, cognitivo, cultural, linguístico e social do povo surdo. Conforme Vigotsky (2008), o significado das palavras pressupõe o desenvolvimento da atenção, memória lógica, abstração e capacidade de comparar e diferenciar. Dessa forma, tem-se a escrita de sinais como possibilidade de acesso igualitário ao desenvolvimento intelectual, à aprendizagem e ao letramento em sua primeira língua permitindo ao surdo construir, manifestar e registrar suas produções, marcando a história com seus escritos, tendo sua língua valorizada em diferentes modalidades.

Assim, diante dos resultados obtidos e comparados, ficou evidente a eficiência no processo de aprendizagem da língua de sinais na modalidade escrita, tendo a necessidade de estudos cada vez mais profundos nesse campo de conhecimento, para que através dos resultados positivos encontrados os surdos consigam ter maior e melhor acesso a educação por meio de sua própria língua.

\section{Conclusão}

O estudo enquanto continuidade de outros três realizados no ano de 2016, sobre a escrita de sinais, conseguiu confirmar os dados encontrados nas mesmas, uma vez que revelou a eficiência da aprendizagem da escrita da língua de sinais para os surdos, contribuindo para a formação dos mesmos enquanto sujeitos letrados e alfabetizados, promovendo uma aprendizagem significativa que dialoga com os elementos necessários ao seu desenvolvimento.

É destacável que a escrita faz parte da constituição dos indivíduos letrados, sendo ela um instrumento cultural que marca positivamente uma comunidade e por isso é de suma importância também para a comunidade surda, dando aos mesmos o poder de interagir de todas as formas com os seus pares compreendendo e interpretando melhor a sua língua numa mesma perspectiva de oportunidade que é dada aos ouvintes.

Para isso, é importante que os professores, especialmente o de Libras e de língua portuguesa para surdos, busquem formação adquirindo conhecimento da escrita de sinais no sistema Signwriting para que consigam 
desenvolver metodologias que atendam às necessidades linguísticas no campo da escrita do povo surdo. Com esse instrumento podem buscar recursos diferenciados que coloquem a língua de sinais como língua natural possível de ser aprendida na modalidade visual-espacial e escrita difundindo o conhecimento.

Desta forma, é possível destacar os aspectos positivos do ensino da língua de sinais na modalidade escrita o qual corrobora positivamente para o amplo desenvolvimento psicológico e cognitivo do surdo, sendo necessário o desenvolvimento de matérias didáticos que ampliem as possibilidades de trabalho com a escrita de sinais, incluindo a mesma em todas as áreas do conhecimento presentes do ambiente escolar e na sociedade em geral.

\section{Referências}

ALVES, Risolene J. O Processo de Aquisição da Escrita de Sinais. Trabalho de Conclusão de Curso (Graduação). João Pessoa. Universidade Federal da Paraíba, 2016. 22f.

ALVES, Edneia O.; ALBERTO, Maria F. P. Língua como singularidade na política educacional para surdos. Revista linguagens \& letramentos, Universidade Federal de Campina Grande, Cajazeiras, v. 1, n. 2, p. 167-190, 2016. Disponível em: http://revistas. ufcg. edu.br/ cfp/index.php/. Acesso em 09, jun, 2020.

;ALBERTO, Maria F. P. Vivência educacional do surdo usuário de Libras. Revista linguagens \& Letramentos, Universidade Federal de Campina Grande, Cajazeiras, , v. 4, n. 1, p. 165-188, 2019. Disponível em: http://revistas.ufcg. edu.br/cfp/index. php/ linguagens letramentos/ article/view/1337/532. Acesso em 09, jun, 2020.

PAIXÃO, Ezequiel A. L. MOURA, Janilson N. STUMPF, Marianne R. SOUZA, Willames P. Uma Experiência com a Escrita de Sinais. In: ALVES, Edneia O. (Org). A extensão universitária: fonte de conhecimento para área de Libras [recurso eletrônico]. 1 ed. João Pessoa: Ideia, 2015. p. 99 - 122.

ARAÚJO, Aneide O.; OLIVEIRA, Marcelle C. Tipos de pesquisa. Trabalho de conclusão da disciplina Metodologia de Pesquisa Aplicada a Contabilidade Departamento de Controladoria e Contabilidade da USP. São Paulo, Mimeografado, 1997. 
BRASIL. Lei no 10. 436, de 24 de abril de 2002. Dispõe sobre a Língua Brasileira de Sinais - Libras e dá outras providências. Brasília: Senado Federal, 2002. Disponível em: <http://www.planalto.gov.br/ccivil_03/LEIS/2002/L10436. Acesso em 20, mar, 2017.

Decreto 5.626, de 22 de dezembro de 2005. Regulamenta a Lei no 10.436. Diário Oficial da União, Brasília, DF, 2005. Disponível em: <http://www.planalto.gov.br/ ccivil_03/_ato 20042006/2005/decreto/d5626.htm>. Acesso em 28, mar, 2017.

BRANCO, Angela U; SALOMÃO, S. Cooperação, competição e individualismo: pesquisa e contemporaneidade. Periódicos Eletrônicos em Piscologia, Sociedade Brasileira de Psicologia, Ribeirão Preto-SP, v. 9, n. 2, p. 11-18, 2001.

CAPOVILLA, Fernando C.; RAPHAEL, Walkiria D. Dicionário Enciclopédico Ilustrado Trilíngue da Língua de Sinais Brasileira. São Paulo: Editora da Universidade de São Paulo, 2008. Volume I, 3 ed.

DALLAN, Maria S. S. Signwriting: escrita visual para a língua de sinais - o processo de sinalização escrita. In: II Congresso Nacional de Surdez, São José dos Campos, São Paulo, 2009. Disponível em: http://escritades.dominiotemporario.com /doc/ SIGNWRITING ARTIGO.pdf. Acesso em 08, mai, 2017.

ENCARNAÇÃO, Emmanuelle O. A Aplicabilidade do Ensino da Escrita de Sinais para o Surdo. 2016. 33 f. Trabalho de Conclusão de Curso (Graduação), João Pessoa. Universidade Federal da Paraíba.

GIL, Antônio C. Como elaborar projetos de pesquisa. São Paulo. Atlas, 1991.

LEAL, Sandra R. F.; NASCIMENTO, Maria I. M. A importância do ato de ler: aproximações e distanciamentos teóricos-metodológicos em Paulo Freire. Revista Pro-posições, Unicamp - Faculdade de Educação - FE, Campinas, v. 30, 2019. Disponível em: https://doi.org/10.1590/1980-6248-2018-0024. Acesso em 09, jun, 2020.

LEDERBERG, Amy. R, SCHICK, Brenda; SPENCER, Patrícia. Language end Literacy development of deaf and hard-of-hearing children: successes ad challenges development. Developmental Psychology, American Psicological Association, England, n. 49, v. 1, 2013. Disponível em: https://pubmed.ncbi.nlm.nih.gov/22845829/. Acesso em 09, jun, 2020.

LIMA, Marleide F. Escrita de Sinais: Uma Proposta de Alfabetizar os Surdos em L1. Trabalho de Conclusão de Curso (Graduação). João Pessoa. Universidade Federal da Paraíba, 2016. 25 f. 
Surdos em L1. Revista Prática Docente, Instituto Federal de Mato Grosso, Cuiabá, v. 3 n. $1 . \quad$ p. $140 \quad-\quad 157.2018$. Disponível em: http://dx.doi.org/10.23926/RPD.2526-2149.2018.v3.n1.p140-157.id162 . Acesso em: 09 jun. 2020.

MARCUSCHI, Luiz A. Da fala para a escrita: atividades de retextualização. São Paulo: Cortez, 2001.

MORAIS, Carla D. Escrita de sinais: supressão de componentes quirêmicos da escrita de sinais da Libras em SignWriting. Florianópolis. Tese (Doutorado em Linguística). Programa de Pós-gradução em Linguística, Universidade Federal de Santa Catarina, 2016.

OLIVEIRA, Christinne F. S. Análise da Escrita de Sinais SignWriting presente na obra literária Rapunzel Surda. Trabalho de Conclusão de Surdo. João Pessoa: UFPB, 2016.

OLIVEIRA, Marta K. Vygotsky aprendizado e desenvolvimento. um processo sócio-histórico. São Paulo: Scipione, 1997.

PAIXÃO, Ezequiel A. L; ALVES, Edneia O. Libras em suas modalidades artefatos linguísticos da comunidade surda. In: PEIXOTO, Janaína A.; VIEIRA, Maysa R. (Org). Artefatos culturais do povo surdo: discussões e reflexões. João Pessoa: Sal e terra, 2018. p. $47-60$.

PIAGET, Jean. O nascimento da inteligência na criança. Tradução Álvaro Cabral. Rio de Janeiro: Zahar, 1970.

QUADROS, Ronice M; SCHMIEDT, Magali L. P. Idéias para ensinar português para alunos surdos. Brasília: MEC, SEESP, 2006.

REILY, Lúcia Helena. As imagens. o lúdico e o absurdo no ensino de arte para Pré- escolares surdos. In: SILVA, Ivani. R., KAUCHAKJE, Samara.; GESUELI, Zilda. M. (Orgs.). Cidadania, Surdez e Linguagem: desafios e realidades. São Paulo: Plexus Editora, 2003. p. 161-192.

STROBEL, Karin L. As imagens do outro sobre a cultura surda. Florianópolis: Editora UFSC, 2009.

STUMPF, Marianne R. Transcrições de língua de sinais brasileira em signwriting. In: LODI, Ana C. B., HARRISON, Kathryn, M. P., CAMPOS, Sandra. R. L.; TESKE, Ottmar. Letramento e minorias. Porto Alegre: Mediação, 2013.

SELLTIZ, Clarie; WRIGHTSMAN, Lawrence. S.; COOK, Stuart W. Métodos de pesquisa das relações sociais. São Paulo: Herder, 1965. 
VYGOTSKY, Levy S. Pensamento e linguagem. São Paulo: Martins Fontes, 2008.

Recebido em 29 de abril de 2020.

Aceito em 20 de junho de 2020. 